distribution of the buffering capacity between people (determination of the environmental space) which does not mean only the execution of the "division operation", but also the existence of the will of the people to commit themselves to worked-out division rules. The people's good will should be based on the understanding, on the integrated and systematized, presented in an understandable manner, information and the availability of it.

In Estonia the sustainable development is endangered mostly by the concentration of industrial production and, as a result of it, also the consumption of natural resources (especially water) and environment pollution in Northeast of Estonia, which represents about $7 \%$ of the geographical area of the country and where nearly one third of Estonian industry, primarily oil shale mining and processing, is concentrated. The environmental problems caused directly by oil shale industry, are covered $11 \%$ of the territory of the district, but the problems related with overconsumption and pollution of water and emission of $\mathrm{CO}_{2}$ by oil shale burning overspread the borders of the district.

The aim of present study is to discuss main problems affecting the sustainability of the natural environmental systems in their entirety, considering both local (Ida-Viru district and Estonia), regional (the Baltic Sea catchment are) and global pecularities. The quantitative descriptions of global and Estonian carbon and water cycles will be given. Environmental space and the ecological footprint will be defined and shown how to calculate them. An overview of legal and economic mechanisms developed for the regulation of carbon and water cycles will be given $\left(\mathrm{CO}_{2}\right.$-tax, etc.), relevant calculating algorithms will be given. The development problems of Estonian oil shale energetics from the point of view of quantitative indicators of sustainability and also throuh prism will be presented. In the frame of the study the quantitative assessment principles will be dealt both on global and local (the catchment area of the Baltic Sea, Estonia and regions) levels showing the interdependences of the problems encountered at different levels. As great environmental problems in Estonia are concentrated in Ida-Virumaa, a special attention will be drawn to the oil shale mining and energetics.

\title{
ДЕСЯТЬ ЛЕТ ПЛАТНОГО ПРИРОДОПОЛЬЗОВАНИЯ В ЭСТОНИИ
}

\author{
ЭНHО РEЙHCAJTY \\ Таллинский Технический Университет, Горный институт, \\ Копли 82, Таллинн 10412, ЭСТОНИЯ
}

С конца восьмидесятых годов в Эстонии действует система платежей за пользование природными ресурсами. Ввод системы поставил перед собой задачу сократить эксплуатацию минеральных ресурсов и ограничить загрязнение природной среды. Платежи были установлены на добычу полезных ископаемых, выкачивание вод, спуск сточных вод в водоемы, загрязнение воздуха и складирование отходов. Все перечисленные виды платежей автор трактует как единую систему платного природопользования. Ведь по существу, также как ресурсом горной промышленности является полезное ископаемое, так и водоемы и атмосфера, куда выбрасываются отходы, можно рассматривать как промышленное звено производства. Иными 
словами, используя окружающую среду в качестве очистительного сооружения или свалки, промышленник употребляет природу в качестве технологического звена, за что он не выложил капитал. За это и надо платить. Кому? Очевидно обществу, который согласно § 5 Констутуций Эстонии яляется владельцем всех природных богатств и ресурсов.

Примеры о величине нормативов платежей в Эстонии приводятся в таблице 1. Полезно знать, что эстонская крона (ЕEK) равна 1/8 DEM.

Наиболее специфическим из всех налогов является плата за пользование минеральными ресурсами, именуемая также горной рентой. Этот вид платежей (royalty) общеизвестна в горной экономике всего мира. В бывшем СССР она не применялась ввиду несовместимости с властвующей экономической теорией. В период восстановления рыночной экономики в Эстонии восстанавливалась и горная рента. За основу были приняты разные теоретические позиций. Применительно к горючему сланцу автор данной статьи исходил из желания выравнивать воздействие трех производстенных ресурсов - капитала, трудовых и природных. Составители нормативов горной ренты по остальным полезным ископаемым взяли за основу теорию дифференциальной ренты.

Первоначально горная рента, как и другие платежи за природопользование были двухпозиционными. Под этим термином подразумевается, что в пределах лимита (дозволенного) природопользования (объема добычи, выкачки или сброса воды, выбросов в атмосферу) действует один, нормальный тариф. Выше лимита действует n-кратный тариф, посуществу штраф, так как в этом случае плата отнимается от чистой прибыли.

Платежи за пользованием минеральными ресурсами и воды, а также за загрязнение воздуха и водоемов, накопляются частично в местный бюджет, частично в Фонд охраны природы (ФОП). Этот фонд не входит в состав государственного бюджета, а подкрепляет сферу деятельности Министерства окружающей среды Эстонии. Из фонда финансируются в основном природоохранные мероприятия.

В период освоения система платного природопользования действовала достаточно эффективно как регулирующий фактор. Однако со временем все больше и больше выявлялся ее фискальный характер. При этом, по мнению автора, горная рента полностью теряла свое положительное значение в национальной экономике. В первую очередь, по мнению автора, погрешность в том, что конкретно рассматриваемая система налогообложения находится в ведомо министерства окружающей среды, а не министерств финансов и экономики, которые администрируют экономику в Эстонии. К тому же, ввиду технических и юридических сложностей первоначально двухпозиционная горная рента превратилась простым, неуправляющим и неуправляемым налогом.

Кроме того, десятилетная практика показала, что система платного природопользования в Эстонии далеко не совершенна. Явно выявились такие отрицательные стороны как примитивизм в фискальном и экономическом смысле и субъективизм относительно отдельных видов промышленности. Ниже приводятся некоторые моменты несовершенства системы по части горной ренты, то есть в области специализаций автора данной статьи. При 
этом не упускается из вида обязанность при необходимости иллюстрировать высказанное конкретными цифрами.

Нормативы горной ренты назначаются на основе двух-трех показателей качества полезного ископаемого, определенных в ходе геологоразведки, в частности применительно к устаревшему способу их использования.

Горная рента не учитывает место расположения залежи полезного ископаемого - находится она в регионе с развитой промышленностью или далеко от путей сообщения. Как правило, это затрудняет эксплуатацию удаленных месторождений.

За основу горной ренты берется кажущийся, а не экономически целесообразный объем полезного ископаемого. Например не принимается в учет выход полезного продукта, даже если это известно по геологопезведке.

Одно и то же полезное ископаемое, в частности одной и той же залежи, может быть наложено разными нормативами платежеи, например глина в зависимости от того, добывает ее цементная или керамическая промышленость.

Осушение торфянников (торф в Эстоний приравнивается $\mathrm{k}$ минеральным полезным ископаемым) не рассматривается как выкачивание воды из карьеров.

Налогом облагают только те сульфаты, которые выбрасываются промышленностью, а не те, которые загрязняют воды из сельскохозяйственных мелиоративных систем.

При назначении нормативов платежей в первую очередь имеется в виду ожидаемая масса денег в ФОП, частично и в местные бюджеты. Позтому бывает, что небольшие производители несут часто большую налоговую нагрузку, чем крупные, в частности государственные.

Эти отрицательные стороны горной ренты и некоторые судебные процессы вокруг других платежей природопользования в Эстонии говорят о том, что наступило время критически пересмотреть практику наложения платежей на природные ресурсы производства. Вопрос становится все более актуальным по мере приближения Эстонии к Евпопейскому Союзу.

На пути совершенствования системы увидим два направления. Первое предусматривает установление горной ренты в зависимости от эффективности производства, на основе бизнес-плана освоения месторождения. Такое практикуется в странах с развитой горной промышленностью применительно к ценным полезным ископаемым. Вторым может быть полный отказ от горной ренты. Это тоже практикуется в горной экономике мира. Тот и другой путь соответствует Закону о недрах Эстонии и при соблюдении законов не угрожает убытками национальной экономике. 
Таблица 1

Примеры нормативов платежей за использование природных ресуров в Эстонии с 01.01.1999 г. до 01.01.2000 г.

\begin{tabular}{|c|c|c|}
\hline Ресурсы, загрязнители & Единица & $\begin{array}{c}\text { Норматив } \\
\text { ЕЕК/ед }\end{array}$ \\
\hline $\begin{array}{l}\text { Использование вод } \\
\text { поверхностных } \\
\text { в Т.ч. в качестве охлаждающей воды } \\
\text { глубинных из различных горизонтов } \\
\text { минеральных } \\
\text { Выкачивание воды из шахт и карьеров } \\
\end{array}$ & $\begin{array}{l}M^{3} \\
M^{3} \\
M^{3} \\
M^{3} \\
M^{3}\end{array}$ & $\begin{array}{c}0,10.0,20 \\
0,02 \ldots 0,025 \\
0,20 \ldots 0,70 \\
15 \\
0,03 \\
\end{array}$ \\
\hline $\begin{array}{l}\text { Загязнение поверхностных вод и водоносных горизонтов }{ }^{1} \\
\text { фенолами } \\
\ldots \\
\text { нефтепродуктами } \\
\ldots \\
\text { сульфатами } \\
\end{array}$ & $\mathrm{T}$ & $\begin{array}{r}12622 \\
3306 \\
22 \\
\end{array}$ \\
\hline 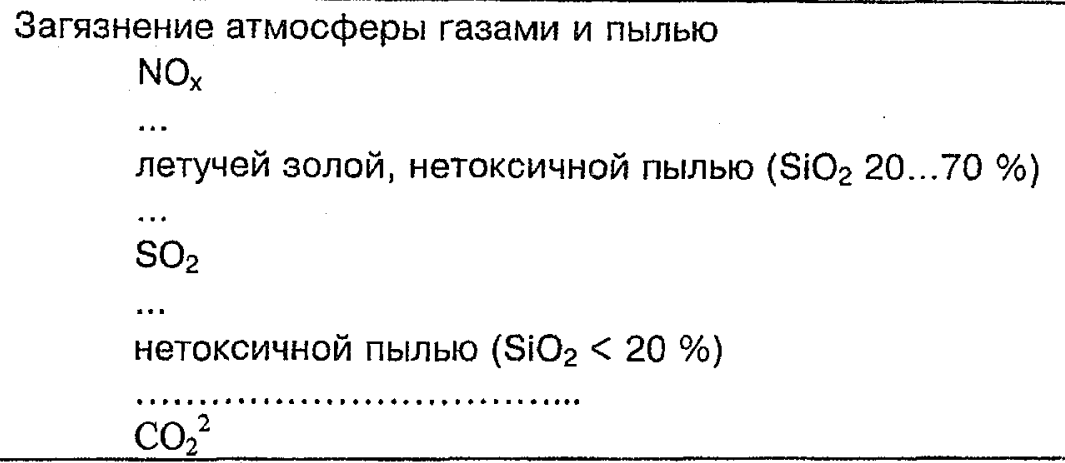 & ò & $\begin{array}{c}105,4 \\
46 \\
46 \\
33 \\
0 \\
\end{array}$ \\
\hline $\begin{array}{l}\text { Складирование отходов } \\
\text { инертных (безопасных) } \\
\ldots \\
\text { умеренно опасных } \\
\ldots \\
\text { особоопасных } \\
\ldots \\
\text { отходов сланцевой промышленности } \\
\end{array}$ & $\mathrm{T}$ & $\begin{array}{c}1,60 \\
13,10 \\
1317,40 \\
0,60 \ldots 5,20 \\
\end{array}$ \\
\hline $\begin{array}{l}\text { Добыча полезных ископаемых } \\
\text { глин различных } \\
\text { торфа } \\
\text { строительных известняков и доломитов } \\
\text { песков различных } \\
\text { горючего сланца } \\
\text { цементного и технологических известняков } \\
\text { гравия } \\
\text { облицовочных известняков и доломитов } \\
\text { технологических доломитов }\end{array}$ & $\begin{array}{l}M^{3} \\
T \\
M^{3} \\
M^{3} \\
T \\
M^{3} \\
M^{3} \\
M^{3} \\
M^{3}\end{array}$ & $\begin{array}{c}1,15 \ldots 3,90 \\
1,80 \ldots 3,00 \\
2,40 \ldots 3,90 \\
3,90 \ldots 4,70 \\
4,00 \\
5,90 \\
6,00 \\
7,80 \\
14,50 \\
\end{array}$ \\
\hline
\end{tabular}

\footnotetext{
1 платежи за загряжнение вод, так как и атмосферы, дифференцируются с помоцью системы различных коэффициентов

2 платежи за $\mathrm{CO}_{2}$ ведутся, начиная с 01.01 .2000 r. в размере $5 \mathrm{EEK} / \mathrm{T}$, применительно $\mathrm{K}$ топливным установкам с суммарной тепловой мощностью не менее $50 \mathrm{MW}$
} 